\title{
Studying of solar-terrestrial connections in the dynamics of the surface atmospheric electric field
}

\author{
Tatyana Kudrinskaya ${ }^{* * *}$, Gennady Kupovykh ${ }^{1}$, Anatoly Adzhiev ${ }^{2}$, Bulat Zainetdinov ${ }^{3}$ \\ ${ }^{1}$ Southern Federal University, Taganrog, Russian Federation \\ ${ }^{2}$ High-mountain geophysical Institute, Federal service for hydrometeorology and environmental \\ monitoring, Nalchik, Russian Federation \\ ${ }^{3}$ Voeikov Main Geophysical Observatory, Federal service for hydrometeorology and environmental \\ monitoring, Saint Petersburg, Russian Federation
}

\begin{abstract}
The paper presents the results of the analysis of variations in the electric field intensity of the surface atmosphere obtained in highlatitude, high-altitude and lowland observation points, together with the parameters of solar and geomagnetic activity.
\end{abstract}

\section{Introduction}

At present, in the conditions of global and regional climate changes, solar-terrestrial connections have an undeniable influence on the weather and climate of the Earth. The problem of studying the relationship of solar activity with weather events and climate, both in the short and long term, is the mechanisms of its effects on the atmosphere that are not fully understood. One of these mechanisms that can explain the influence of solar activity on meteorological and climatological processes can be the atmospheric global electrical circuit, whose characteristics are related to the parameters of solar activity, planetary indices, and the intensity of galactic cosmic rays.

The solar effect on the electrical state of the atmosphere is caused by short-wave and $\mathrm{x}$ ray radiation, the action of solar cosmic rays and solar wind. At the same time, the impact of these factors is largely determined by the cycle of solar activity, the rotation of the Sun and Earth, and the variability of the solar atmosphere. Current research shows that the impact of solar activity on the state of the surface atmosphere is manifested in different time ranges

\subsection{Theoretical bases}

The influence of solar activity on the state of the lower atmosphere may be related to variations in the parameters of the global electric circuit (GEC). First, the high layers of the atmosphere are ionized mainly by ultraviolet and x-ray radiation from the Sun. Second, variations in cosmic ray flows can have a sufficient effect on the conductivity of the

\footnotetext{
* Kudrinskaya T.: tvkudrinskaya@sfedu.ru
} 
atmospheric column and modulate the intensity of the electric current in the planetary circuit, as well as the electric field in the "fair weather" regions. The electric field intensity is modulated by the rate of atmospheric ionization and changes in the ionospheric potential $[1,2]$. Galactic cosmic rays (GCR), solar protons, and electrons of the Earth's radiation belts change the rate of atmospheric ionization, and changes in the ionospheric potential can occur due to geomagnetic disturbances. Note that the variations of the GCR flow are in the opposite phase with the 11-year cycle of solar activity: at the minimum of solar activity, the interplanetary medium is weakly disturbed and the cosmic ray flows are maximum. In turn, there is a connection between the atmospheric electric field and the intensity of cosmic radiation: the atmospheric electric field decreases almost immediately after the Forbush effect in the GCR and is restored within a few days [3].

\subsection{Experimental studies}

Observations of the atmospheric electric field strength at the stations (Verkhne Dubrovo, Tiksi) of the network of Federal service for hydrometeorology and environmental monitoring (Roshydromet) were made by automated meters "POLE-2M" [4]. The electric field meter EFM 550 (Vaisala company) was used to register the electric field strength at the high-altitude station Peak Cheget (High-mountain geophysical Institute, Roshydromet) [5].

The high-altitude station Peak Cheget is characterized by the absence of strong sources of radioactive radiation and a low content of aerosol particles in the atmosphere $[6,7]$. The Tiksi polar station is located far from major industrial centers, which, in turn, also excludes strong anthropogenic influence [8]. Verkhne Dubrovo station is one of the typical continental stations. The distance from major industrial centers allows us to exclude the anthropogenic component in the formation of the electrical state of the surface layer. The main characteristics and a brief description of the observation points are shown in table 1.

Table 1. Description of observation points.

\begin{tabular}{|c|c|c|c|c|}
\hline $\begin{array}{c}\text { Observation } \\
\text { points }\end{array}$ & latitude & longitude & $\begin{array}{c}\text { height } \\
\text { above sea } \\
\text { level, } \mathbf{~ m}\end{array}$ & Description \\
\hline Verkhne Dubrovo & 57,6 & 61,1 & 288 & $\begin{array}{c}\text { The station is located in the middle of a } \\
\text { forest area at a distance of 30 km East of } \\
\text { Yekaterinburg }\end{array}$ \\
\hline Tiksi & 71,6 & 128,9 & 7 & $\begin{array}{c}\text { The station is located in the polar region, on } \\
\text { the coast of the Arctic ocean (on the shore } \\
\text { of the bay of the same name) }\end{array}$ \\
\hline Peak Cheget & 43,2 & 42,3 & 3050 & $\begin{array}{c}\text { The station (3040 m above sea level) is } \\
\text { located on the Northern slope of Cheget } \\
\text { mountain in the Elbrus region }\end{array}$ \\
\hline
\end{tabular}

The behaviour of the atmospheric electric field near the earth depending on the dynamics of solar activity is studied in this paper. The values of solar activity characteristics are obtained using the Geostationary Operational Environmental Satellite (GOES15 and GOES14) [9].

At present, the dynamics of solar activity can be expressed not only by the number of sunspots (wolf numbers), but also by the density of the radio emission stream at a wavelength of $10.7 \mathrm{~cm}$. The analysis of observations shows that the relationship between these characteristics is quite strong and stable [10]. The radio emission flux density (p) is measured in solar units of flux ( 1 s.u.f. $\left.=10^{-22} \mathrm{~W} / \mathrm{m}^{2}\right)$ and varies widely from 50 to 300 s.u.f.

To characterize the solar flare activity, the x-ray flux is used. Depending on the power of $\mathrm{x}$-ray radiation, solar flares are divided into classes, denoted by an uppercase Latin letter 
(A, B, C, M, X) and a number ranging from 1 to 9.9 , which determines the value of the flow: $\mathrm{A}(1-9)=(1-9) \cdot 10^{-8} \mathrm{~W} / \mathrm{m}^{2}, \mathrm{~B}(1-9)=(1-9) \cdot 10^{-7} \mathrm{~W} / \mathrm{m}^{2}, \mathrm{C}(1-9)=(1-9) \cdot 10^{-6} \mathrm{~W} / \mathrm{m}^{2}, \mathrm{M}(1-$ $9)=(1-9) \cdot 10^{-5} \mathrm{~W} / \mathrm{m}^{2}, X(1-\mathrm{n})=(1-\mathrm{n}) \cdot 10^{-4} \mathrm{~W} / \mathrm{m}^{2}$. In addition, you can use the flash activity index (from 0 to 10) as an integral characteristic of the presence and intensity of solar flares. Based on observations, we can speak of a positive dependence of the solar radiation flux at a wavelength of $10.7 \mathrm{~cm}$ on the flash activity index [11].

To estimate the reaction of the Earth's magnetic field to the activity of the Sun, the planetary index $\left(A_{p}\right)$ is used, which represents the average level of geomagnetic activity. Values of the $A_{p}$-index (in $\mathrm{nTl}$ ): from 0 to 7 - a calm state of the ionosphere, from 15 to 20 an unstable, active state, and values greater than 35 correspond to a magnetic storm.

This work is a continuation of the research started earlier. The results presented below are in good agreement and support the conclusions indicated in $[11,12]$.

\section{Results and discussion}

In 2020, the next cycle of solar activity is coming to an end, the maximum of which was in 2014, and the minimum was in 2019. Table 2 shows some characteristics of solar activity for the summer season (June-August) for 2014 (maximum) and 2017 (closer to the minimum).

Table 2. Average values of the parameters of solar activity.

\begin{tabular}{|c|c|c|c|}
\hline \multicolumn{2}{|c|}{ Parameter } & 2014 & 2017 \\
\hline \multicolumn{2}{|c|}{ Number of sunspots (average) } & 60 & 10 \\
\hline \multicolumn{2}{|c|}{ Solar radio flux (average), $10^{-22} \mathrm{~W} / \mathrm{m}^{2}$} & 140 & 80 \\
\hline \multirow{3}{*}{$\begin{array}{l}\text { Number of solar flares } \\
\text { (total) }\end{array}$} & $\mathrm{C}$ & 476 & 166 \\
\hline & $\mathrm{M}$ & 71 & 31 \\
\hline & $\mathrm{X}$ & 9 & 4 \\
\hline
\end{tabular}

On the basis of experimental data, the features of characteristic values and variations of the atmospheric electric field intensity for the periods of maximum and minimum solar activity are studied.

Figure 1 shows graphs of atmospheric electric field intensity values for different numbers of spots on the Sun's surface in the year of active Sun (2014), and the values for 2017 are indicated by an asterisk.

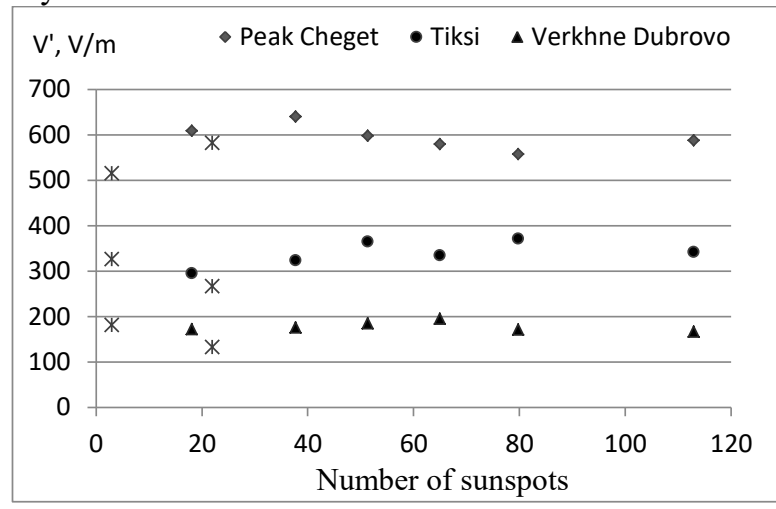

Fig. 1. Average values of the atmospheric electric field for different values of the number of sunspots

For the Peak Cheget high-altitude point, when the number of sunspots is from 30 to 80 , it is typical to reduce the values of the electric field strength. A similar tendency to decrease the values of the electric field strength of the surface layer of the atmosphere with an increase in the number of sunspots at the Peak Cheget station (for 2012, 2013) was 
presented earlier [12]. For the Tiksi polar station, on the contrary, there is a slight increase in the electric field, while for the Verkhne Dubrovo continental station, the values of the field strength practically do not change relative to the average value.

A similar behavior of the electric field is observed when comparing its values with the flux density (p) of solar radio radiation at a wavelength of $10.7 \mathrm{~cm}$ figure 2 shows the change in the electric field strength at different $p$ values for the summer season of 2014.

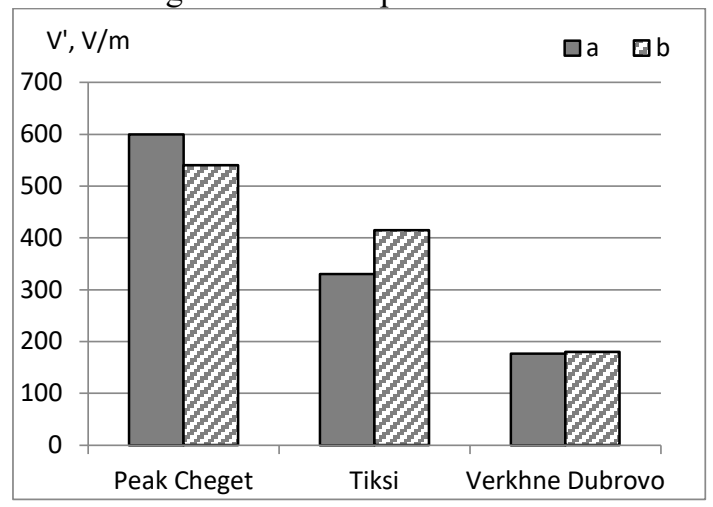

Fig. 2. Average values of the atmospheric electric field for different values of the radio emission flux: a) $80 \div 150 \cdot 10^{-22} \mathrm{~W} / \mathrm{m}^{2}$, b) $180 \div 230 \cdot 10^{-22} \mathrm{~W} / \mathrm{m}^{2}$

Previously, the influence of the number and power of solar flares on the values of the atmospheric electric field strength was studied [11]. This study used experimental data for periods when powerful solar flares were observed. The main characteristics of class $\mathrm{X}$ outbreaks observed during the summer season are shown in table 3.

Table 3. Characteristics of solar flares

\begin{tabular}{|c|c|c|c|}
\hline Data & Start time, (UT) & $\begin{array}{c}\text { Duration of flare, } \\
\text { min }\end{array}$ & $\begin{array}{c}\text { Power of solar flare, } \\
\mathbf{1 0}^{-4} \mathbf{B} \mathbf{~} / \mathbf{m}^{\mathbf{2}}\end{array}$ \\
\hline $10 / 06 / 2014$ & $11: 36$ & 8 & 2,2 \\
& $12: 36$ & 27 & 1,5 \\
$11 / 06 / 2014$ & $09: 29$ & 11 & 1 \\
\hline $06 / 09 / 2017$ & $11: 53$ & 17 & 9,3 \\
& $09: 57$ & 20 & 2,2 \\
$07 / 09 / 2017$ & $14: 20$ & 35 & 1,3 \\
$10 / 09 / 2017$ & $15: 35$ & 56 & 8,2 \\
\hline
\end{tabular}

Based on the experimental data for summer seasons in 2014 and 2017, obtained at the Peak Cheget mountain station, the dependence of the distribution of the electric field of the atmosphere "fair weather" from the index (Index) flare activity up to 7.5. Figure 3 shows the dependence of the electric field from the index values of flare activity.

The regression line equations approximating the experimental distributions have the form:

$$
\begin{aligned}
& V^{\prime}=620-9,5 \cdot \text { Index, for } 2014 \text { data, } \\
& V^{\prime}=610-20 \cdot \text { Index, for } 2017 \text { data. }
\end{aligned}
$$

Thus, the values of the electric field strength of the atmosphere in the year of the active Sun (2014) are greater, and the tendency to decrease the electric field is more significant when the Sun is calmer (2017). This is due to the large number of days characterized by low outbreak activity: days with Index values less than 1 are equal to $69 \%$ of the total number of cases in 2017 and, respectively, 21\% in 2014. 




Fig. 3. The regression of the atmospheric electric field by the flash activity index

Next, we will consider some features of variations in the electric field strength of the surface atmosphere when observing powerful solar flares of class $X$ and for calm Sun conditions. Figure 4 shows the daily variations of the atmospheric electric field averaged for periods when there were no outbreaks of class $\mathrm{C}$ or higher (the index of flash activity is zero) for 2014 and 2017. In addition, for comparison, the variations in the electric field on the day when the class $\mathrm{X}$ flash was observed are given.



Fig. 4. The variations of atmospheric electric field: a) Peak Cheget, b) Verkhne Dubrovo

Based on the results of earlier studies, the dependence of the electric field strength values on the value of the Ap-index for a high-altitude observation point in the summer months was obtained, and the distribution of electric field values for different States of the 
geomagnetic field at stations of the Roshydromet network was considered. So, for the alpine and polar observation points there is a decrease in the intensity of the atmospheric electric field with increasing activity of the geomagnetic field [11].

In this study, the nature of daily variations of the atmospheric electric field under different geomagnetic activity is investigated. The average daily variations in the atmospheric electric field strength (in \% relative to the average value) for two points (highaltitude and continental) for 2014 are shown in figure 5 at different levels of geomagnetic activity: less than $5 \mathrm{nTl}$ - calm state (dotted line) and $20 \div 30 \mathrm{nTl}$ - unstable state (solid line). Note the following characteristic features: at high values of the Ar index, the values of the electric field strength during the day for a high-altitude point are consistently higher than the average, and for a continental station, on the contrary.

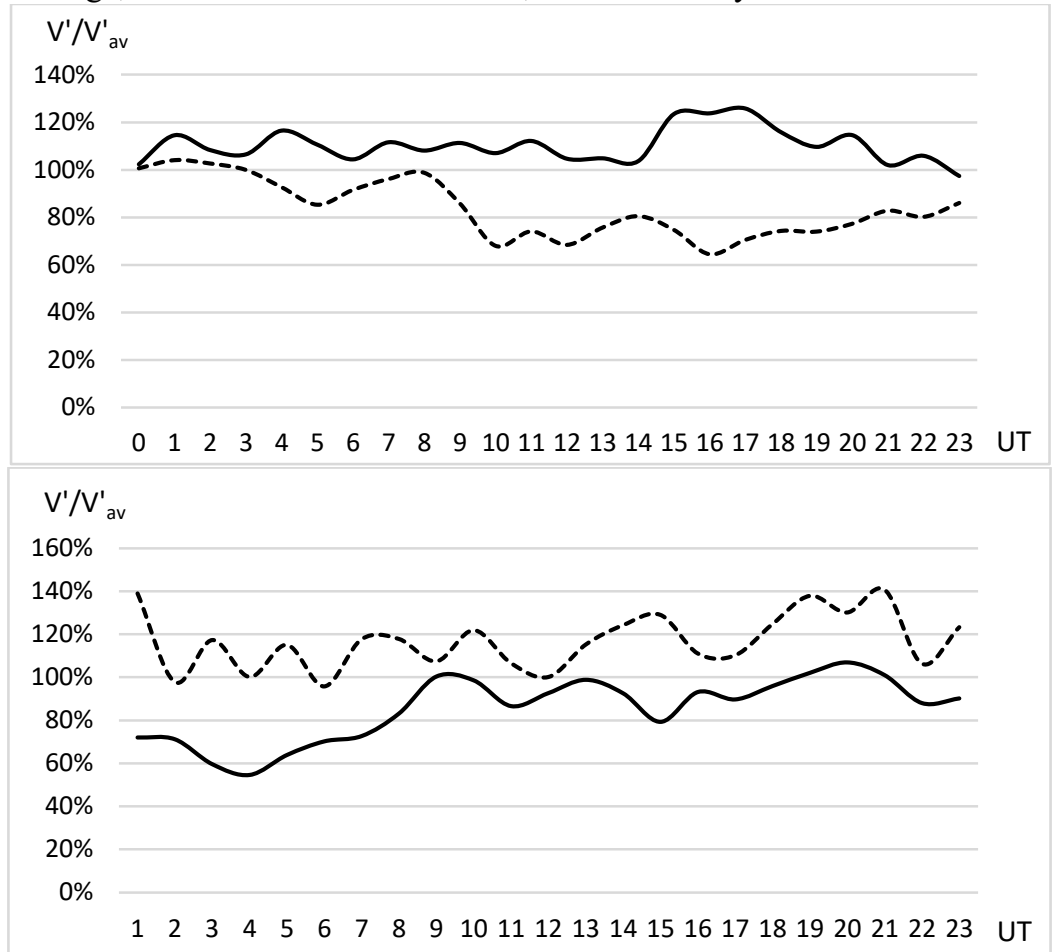

Fig. 5. The variations of atmospheric electric field for different values of Ap-index:

a) Peak Cheget, b) Verhnee Dubrovo

\section{Conclusions}

Thus, data from atmospheric-electrical observations at continental stations in high-latitude, high-altitude and flat zones showed the influence of solar and geomagnetic activity indices on the values and variations of the surface electric field.

\section{References}

1. F.Yu. Tinsley, Eds.J. Pap, et al., Solar variability and its effects on the Earth's atmosphere and climate system, Washington, P. 321339.183 (2004)

2. B.A. Tinsley, Rep. Progress Phys., 6, 066801 (2008) 
3. V. Kuznetsov, N. Cherneva, Bulletin of KRAESC, Earth Sciences, vol.11, no. 1, pp.89-97, (2008) in Russian

4. L. Sokolenko, B. Zainetdinov, Proceedings of GGO, vol.589, pp.153-166, (2018) in Russian

5. A.Kh. Adzhiev, G.V. Kupovykh, Izvestiya. Atmospheric and Oceanic Physics, T.51. №6. pp.633-638 (2015)

6. A.Kh. Adzhiev, G.V. Kupovykh, Doklady Earth Science, vol.462, no.1, pp.502-504 (2015)

7. G.V. Kupovykh, T.V. Kudrinskaya, et al., IOP Conference Series: Materials Science and Engineering (2019)

8. B.G. Zainetdinov, Proceedings of GGO, vol.588, pp.47-61, (2018) in Russian

9. LPI Solar X-ray Astronomy Laboratory, URL: https://tesis.lebedev.ru/

10. A.A. Petrukovich, Plasma heliogeophysics, Solar-earth connections and space weather, Nauka, pp.175-257, (2008)

11. G.V. Kupovykh, T.V. Kudrinskaya, et al., Proceedings Russian Open Conference on Radio Wave Propagation (2019)

12. T. Kudrinskaya, G. Kupovykh, A. Redin, Proceedings of higher educational institutions. Physics, vol.59, no.12/3, pp.215-219, (2016) in Russian 